\title{
¿Es posible enseñar teología hoy?
}

\author{
Víctor Codina, S. J., \\ Universidad Católica Boliviana, \\ Centro de Espiritualidad Ignaciana, \\ Cochabamba, Bolivia.
}

La pregunta parecerá menos extraña si recordamos que el mismo Santo Tomás se cuestiona si es posible que alguien enseñe algo a alguien: "Utrum unus homo possit alium docere". . No podemos dar por supuesto que alguien pueda enseñar algo a otro y éste pueda aprender. El profesor ha de poseer no sólo ciencia, sino una pedagogía especial para enseñar, y el discípulo debe poseer la docilitas, la capacidad de ser enseñado, la docilidad, lo cual no siempre se da. Y mucho menos en temas teológicos, donde se dan por supuestos unos condicionamientos que, sobre todo hoy, no es fácil hallar.

Ya hace más de 60 años Dietrich Bonhoeffer, a sus estudiantes teólogos de su comunidad de Finkenwalde, les exigía que comenzasen a estudiar teología cuando solo podían hacer esto, es decir, cuando les era algo necesario y urgente. $\mathrm{Y}$ en nuestros días Clodovis Boff da una serie de consejos a los futuros estudiantes de teología que van en el mismo sentido:

- hay que comenzar a estudiar teología no como una simple etapa más de un currículum, sino cuando uno comience a tener deseo de profundizar su fe y tenga algunos interrogantes;

- la teología no sustituye a la fe, se edifica sobre la propia fe del alumno, que se fundamenta en la fe de la comunidad, de la propia familia, de cuya fe no hay que avergonzarse, aunque es una fe no reflexionada;

- la teología es una reflexión comunitaria, ya que en ella participan tanto la fe del profesor como la de los alumnos;

* Este texto fue presentado en las Jornadas Teológicas Latinoamericanas, celebradas en Santiago de Chile, del 28 al 31 de octubre de 2009.

1. Suma teológica I, Cuestión 117, a.1. 
- como la teología no sustituye al Misterio, sino que sólo lo acota y ciñe, la teología ha de ser orante, ha de nutrir la vida de fe del teólogo, para que luego pueda ser comunicada a los demás;

- en este sentido, toda teología es pastoral, pero de ello no se deduce que se puedan sacar de la teología esquemas pastorales prácticos, pues lo más práctico para una buena pastoral es una buena teoría teológica;

- en América Latina, los pobres constituyen un lugar teológico privilegiado, un punto de partida y de destino a priorizar: ¿cómo puede el Evangelio ser buena noticia especialmente para los pobres?

- la teología será tanto más rica cuanto más pueda dialogar con el pensamiento tanto antiguo como moderno, pues la teología habla de Dios hablando en lenguaje humano y hablando a seres humanos sobre problemas humanos. De ahí la importancia de conocer filosofía, ciencias humanas, culturas, sociología, ciencias naturales, etc. ${ }^{2}$.

A todas estas consideraciones habría que añadir que el contexto posmoderno actual, la crisis de la Iglesia de cristiandad y el ambiente secular y agnóstico que se respira en muchos lugares hacen que no se pueda dar por supuesto que el alumno tenga una base sólida de fe, sino más bien hay que suponer que se halla cuestionado y problematizado.

Pero más que centrarnos en las condiciones de los alumnos, quisiera abordar el tema de la metodología de la enseñanza de la teología de parte de los profesores, precisamente para poder responder así mejor a las expectativas y situaciones de los alumnos. El fracaso que muchas veces constatamos en nuestras clases de teología, la falta de interés y de motivación de los alumnos, tal vez sea más culpa de nosotros los profesores que de los mismos alumnos.

Esto supuesto, quisiera señalar algunas características hoy necesarias para la enseñanza de la teología. No son problemas meramente pedagógicos, son estrictamente teológicos.

\section{Teología mistagógica}

Entendemos por mistagogía la iniciación al misterio, que para los cristianos es la iniciación al misterio de Cristo, que nos ha sido revelado en la historia de salvación. A través del misterio de Cristo accedemos al misterio del Padre por y en el Espíritu. Es una iniciación a la experiencia fundante del cristianismo, al misterio pascual de la muerte y resurrección del Señor.

2. C. Boff, "Consejos a los futuros estudiantes de teología", Perspectiva teológica 31 (1999), pp. 76-96. 
Teología mistagógica significa, pues, tomar conciencia de que toda teología parte de una experiencia espiritual y debe conducir a ella. Frente a visiones predominantemente doctrinales, morales y rituales de la fe cristiana, hemos de afirmar, con Benedicto XVI, que

no se comienza a ser cristiano por una decisión ética o una gran idea, sino por el encuentro con un acontecimiento, con una Persona, que da un nuevo sentido a la vida y, con ello, una orientación decisiva. ${ }^{3}$

Toda teología auténticamente cristiana brota de una experiencia religiosa de un encuentro con el Señor. Esto vale, evidentemente, para el Nuevo Testamento, donde testigos del Señor comunican a otros lo que han visto y oído (1 Jn 1, 1-3); vale para la teología patrística y medieval; y vale, también, para la teología moderna y contemporánea. En la raíz de toda auténtica teología yace una experiencia mística. Orígenes, Ireneo, Agustín, Basilio, Anselmo, Tomás, Catalina de Siena, Buenaventura, Bernardo, Ignacio, Lutero, Teresa de Jesús, Juan de la Cruz, Teresa de Lisieux, Edith Stein, Juan XXIII, Rahner, Congar y los teólogos del Vaticano II, los grandes teólogos de la liberación... han sido personas profundamente espirituales, místicas. La tan repetida frase de Karl Rahner de que el cristiano del futuro o será místico o no será cristiano, y que por tanto es necesario promover una mistagogía de la $\mathrm{fe}^{4}$, vale de modo muy especial para los teólogos, tanto para los profesores como para los alumnos, lo cual supone que es urgente iniciar a una mistagogía.

De ahí nace la pregunta de hasta qué punto los profesores, al elaborar y enseñar nuestra teología, partimos de esta experiencia fundante, si iniciamos a nuestros alumnos a esta experiencia espiritual, de modo que la teología se les convierta en vida, mística, experiencia profunda, que alimente su vida espiritual y futura pastoral. Por esto, toda teología tiene que ser, como decía Rahner, una kniende Theologie, una teología de rodillas, en silencio, en oración. Los Padres de la Iglesia, en el catecumenado, reservaban a las catequesis mistagógicas de la semana de Pascua "in albis" la explicación más profunda sobre los sacramentos de iniciación cristiana, pues estaban convencidos de que solo después de haber experimentado estos misterios en la vigilia pascual, los podrían penetrar con más facilidad $^{5}$. Y Rahner preguntaba a la Iglesia alemana en los años 1970:

¿Dónde se habla con lenguas de fuego de Dios y de su amor? ¿Dónde son mencionados los mandamientos de Dios no como un penoso deber que cumplir, sino como la gloriosa liberación del hombre de la angustia vital

3. Benedicto XVI, Dios es amor, n. 1; citado también en Aparecida n. 12.

4. K. Rahner, "Espiritualidad antigua y nueva", en Escritos teológicos, VII, Madrid, 1967, pp. 25-26.

5. Por ejemplo, esto aparece claramente en Cirilo de Jerusalén, "Catequesis mistagógicas del bautismo", en Catequesis I: De las ceremonias del bautismo, n. 1. 
esclavizadora y del egoísmo frustrante? ¿Dónde en la iglesia no sólo se ora, sino que se experimenta la oración como un don pentecostal del Espíritu, como gracia sublime? ¿Dónde hay, por encima de toda inculcación racional de la existencia de Dios, una mistagogía de cara a la experiencia viva de Dios que parta del núcleo de la propia existencia? ¿En qué seminarios se leen aún los clásicos de la vida espiritual con el convencimiento de que también hoy tienen algo que decirnos?

Evidentemente, este tema está estrechamente ligado al divorcio que se ha operado desde la Baja Edad Media entre teología y espiritualidad, que ha producido una teología muy poco espiritual y una espiritualidad devota pero muy poco teológica. La espiritualidad se ha constituido, en muchas facultades, en un dominio propio y aparte, pero no ha llegado a imbuir y transformar la teología que permanece excesivamente fría y racional, incapaz de suscitar entusiasmo y vida. Los profesores somos docentes, pero tal vez poco maestros de sabiduría y menos aún mistagogos. En las facultades de teología académica no suele existir cátedra de pneumatología, y menos aún la pneumatología impregna nuestras clases magistrales con el fuego del Espíritu. ¿Es extraño que nuestros alumnos se aburran en clase?

\section{Teología simbólica}

En una reciente reunión en Guatemala entre representantes de la llamada "teología india" y personeros llegados expresamente desde el Vaticano, estos últimos dijeron que no existía propiamente una "teología india", pues no poseían escritos, ni libros, ni sumas teológicas. Los de la "teología india" respondieron que no se puede universalizar el concepto occidental de teología y que puede haber otras expresiones no escritas ni racionales de la teología que expresan la experiencia de Dios a través de mitos, leyendas, himnos, cantos, ritos, símbolos que se comunican oralmente de generación en generación...

Identificar la teología con la teología occidental grecolatina o europea es empobrecer el sentido de la teología. Jóvenes estudiantes africanos que después del Vaticano II, en pleno auge de la secularización, estudiaban teología en Europa, tuvieron que ser retirados de las facultades teológicas europeas por su superior, porque la teología muy secularizada que recibían les incapacitaba para comunicar la fe a un pueblo que se expresa a través de mitos y símbolos. Lo mismo puede suceder hoy a alumnos de facultades de América Latina que proceden de culturas originarias muy simbólicas, cósmicas y míticas, y a los que a veces iniciamos a una teología sumamente racional, lógica, dogmática, sistemática, que ni les ayuda personalmente ni les faculta para la pastoral. Muchas de estas culturas, en cambio, tienen gran sintonía con la mentalidad semítica y

6. K. Rahner, Cambio estructural de la Iglesia, Madrid, 1974, pp. 105-106. 
bíblica, que se expresa a través de mitos, ejemplos, parábolas, enigmas, sentencias sapienciales, etc. ${ }^{7}$. Un proverbio hebreo dice que los cuentos no son para hacer dormir a los niños, sino para despertar a los adultos.

En este sentido, podríamos aprender de autores teológicos y espirituales del Oriente cristiano en diálogo con las culturas y religiones de Asia. Así, para Anthony de Mello, teología es el arte de narrar cuentos acerca de lo divino, y también el arte de escuchar dichos cuentos. El arte de gustar y sentir en el corazón dichos cuentos, hasta el punto de ser transformado por ellos, es misticismo ${ }^{8}$.

La teología del Denzinger, la teología escolástica, las disquisiciones filosóficas y teológicas sumamente agudas de autores occidentales antiguos o modernos, centroeuropeos o norteamericanos, resbalan a nuestros alumnos, a la gran mayoría no les interesan en absoluto, pues les resultan excesivamente conceptuales y frías, no responden a su problemática. Por el contrario, hechos concretos, anécdotas históricas, cuentos y parábolas, atraen su atención y son capaces de retenerlas y transmitirlas a otros. Son comunicables.

Pero no se trata simplemente de un problema cultural o pedagógico, sino teológico: el Misterio absoluto de Dios sólo puede ser expresado de forma analógica, en mitos, relatos, símbolos, enigmas. Jesús nunca define lo que es el Reino de Dios, sino que explica parábolas y hace milagros que son signos del Reino. ¿Qué son los sacramentos sino símbolos de la presencia y acción del Espíritu en nuestra historia concreta? ¿Por qué el pueblo aprecia tanto los sacramentales —agua bendita, velas, ceniza, palmas, procesiones, campanas, imágenes- sino porque el Misterio se acerca a su sensibilidad concreta y a su vida cotidiana? ¿Qué es la Iglesia sino un sacramento visible e histórico de salvación?

Los Padres de la Iglesia (por ejemplo, Ambrosio) y la Iglesia hasta el primer milenio no elaboraban ni enseñaban a los catecúmenos y neófitos una teología abstracta de la eucaristía en las aulas, sino que explicaban a los fieles en la celebración litúrgica de la eucaristía el sentido de los ritos que estaban viviendo, de modo que la lex orandi fuese realmente la lex credendi y la fundamentación teológica de su misma $\mathrm{fe}^{9}$.

Cuando a Juan XXIII le preguntaron qué era el Concilio Vaticano II que acababa de convocar y él por toda respuesta abrió la ventana y un viento fresco removió los viejos papeles empolvados que estaban sobre la mesa, todo el mundo

7. Puede verse un desarrollo más amplio de este tema en V. Codina, "Una teología más simbólica y popular", en Parábolas de la mina y el lago, Salamanca, 1990, pp. 117-184.

8. A. de Mello, El canto del pájaro, Santander, 1982, p. 12.

9. C. Giraudo, Num só corpo. Tratado mistagógico sobre a eucaristia, São Paulo, 2003. 
comprendió que el Vaticano II quería ser un soplo fuerte del Espíritu en la Iglesia.

Acabemos este apartado con un cuento de De Mello:

Los discípulos tenían multitud de preguntas que hacer acerca de Dios.

Les dijo el Maestro: Dios es el Desconocido y el Incognoscible. Cualquier afirmación acerca de Él, cualquier respuesta a vuestras preguntas no será más que una distorsión de la Verdad.

Los discípulos quedaron perplejos: Entonces, ¿por qué hablas sobre Él?

¿Y por qué canta el pájaro?, respondió el Maestro.

Y De Mello comenta: "El pájaro no canta porque tenga una afirmación que hacer. Canta porque tiene un canto que expresar"10.

\section{Teología narrativa}

Esta dimensión de la teología está estrechamente ligada a la anterior, pero merece una especial atención, porque, a diferencia del cuento o de la parábola, la narración es el relato de algo histórico, de la historia de salvación. Tanto el Antiguo Testamento como el Nuevo Testamento son fundamentalmente relatos, una narración. La historia solo se comunica narrándola, la historia cuenta relatos: "History tells stories". Sobre este punto la teología actual es muy clara: Dios exige ser narrado ${ }^{11}$. La teología, fundamentalmente, estudia relatos de fe, narraciones-testimonio que intentan transmitir no solo informaciones, sino convicciones, quieren comunicar fuerza vital, tienen una finalidad salvífica, se abren al futuro.

El cristianismo no es primariamente una comunidad de argumentación, sino una comunidad de relatos, que narra una experiencia profunda de Dios que sólo se puede comunicar por la narración. No es una táctica de poder, sino de debilidad, sólo puede contar lo que ha escuchado y ha recibido, lo que, a su vez, comunica y relata de nuevo. No tiene más poder que el estatuto de una experiencia espiritual narrada y recontada.

La teología se divorcia de la espiritualidad cuando deja de ser teología narrativa que cuenta lo que pasó a Abrahán, a Moisés, a David, a Pedro, Juan y Santiago,

10. A. de Mello, El canto del pájaro, óp. cit., pp. 16-17.

11. E. Jüngel, Dios como misterio del mundo, Salamanca, 1984. Entre los autores que han trabajado el tema de la teología narrativa, citemos a K. Barth, J. B. Metz, G. Lohfink, B. Sesboüé, C. Théobald, B. Wacker, M. de Certeau, P. Ricoeur, P. Beauchamp, E. Schillebeeckx, C. Duquoc... En América Latina, citemos la reciente y excelente obra de J. M. Siciliani, Teología narrativa. Un enfoque desde las Florecillas de S. Francisco de Asís, Bogotá, 2009. 
a Pablo, y se convierte en un sistema de verdades y dogmas. La anamnesis narrativa de los acontecimientos fundantes se convierte en fuente del anuncio, del kerigma. En el primer kerigma de los Hechos de los Apóstoles, después de Pentecostés, Pedro lo único que hace es relatar los sucesos de la muerte y resurrección de Jesús, y este anuncio traspasa los corazones de sus oyentes, que se sienten no meros oyentes pasivos, sino corresponsables de la muerte de Jesús (Hch 2,34). La Iglesia es una comunidad narrativa, que no cesa de retomar el relato de su propia historia, historia que se va actualizando a través de la lectura de los signos de los tiempos. El Evangelio se va continuamente re-escribiendo.

Pero el centro del relato cristiano es el misterio pascual, la crucifixión y resurrección de Jesús, que es lo que los Evangelios primariamente relatan; los Evangelios son relatos de la pasión y resurrección, a los que se ha añadido la narración de la vida del Jesús histórico de Nazaret. El resucitado es el crucificado y el crucificado es Jesús de Nazaret. Es una narración peligrosa y subversiva, que cada vez que se narra en la Palabra o en los relatos de la liturgia de la eucaristía, nos interpela y provoca una respuesta. Dios ha entrado en nuestra historia, se ha hecho visible, ha muerto y ha sido resucitado. Sólo después de esta narración se podrá comprender la expresión de Juan de que Dios es amor (1 Jn 4, 8).

Evidentemente, la teología narrativa no significa que no se pueda reflexionar luego sobre estos relatos de salvación, pero hay que dar prioridad ontológica y teológica al relato, cosa que no siempre se hace. Nuestra mentalidad occidental grecolatina tiende a presuponer demasiado rápidamente el relato y pasar a la especulación. Hipóstasis, homoousios, unión hipostática, transubstanciación, causa instrumental, materia y forma, infalibilidad ex sese y no por el consensus ecclesiae... son términos que pertenecen a la tradición eclesial, pero que presuponen antes la narración de un relato de salvación. El relato se puede contar a otros, los términos teológicos esencialistas y abstractos no se pueden transmitir oralmente al pueblo.

Detrás y debajo de la teología narrativa está la presencia misteriosa pero real del Espíritu, que guió al pueblo de Israel, que dirigió la vida de Jesús, que le resucitó y que el Cristo resucitado comunicó a los discípulos, hizo surgir la Iglesia y la continúa guiando hasta la escatología. El Espíritu garantiza la verdad de estos relatos, los convierte en vida en los oyentes, los actualiza y transforma en impulso misionero hacia el futuro. La fuerza de los relatos teológicos no proviene del valor lingüístico de la narratología literaria, sino de la fuerza del Espíritu. Por esto en la eucaristía el relato de la última cena está precedido y acompañado de la invocación epiclética al Espíritu. La teología narrativa es cristológica en su contenido y pneumática en su forma.

Para no desviarnos de nuestro propósito de preguntarnos si es posible enseñar teología hoy, hemos de preguntarnos si la teología que enseñamos es básicamente narrativa o es predominantemente una elucubración filosófica, más 
cercana a Atenas que a Jerusalén, más próxima a Aristóteles, Platón, Kant, Hegel, Nietzsche, Freud, Marx, que a Galilea y Nazaret. Tal vez también nosotros, como muchos de nuestros contemporáneos, en el fondo también nos preguntamos si de Nazaret puede salir algo bueno, si tiene sentido que la salvación del mundo esté ligada a un campesino carpintero que vivió hace 2000 años en un rincón del Mediterráneo. Es un escándalo para la razón, una locura para el mundo, pero es la sabiduría de Dios, cuya debilidad es más fuerte que toda la sabiduría humana. Pero esto hay que contarlo, narrarlo una y otra vez.

\section{Teología mayéutica}

La mayéutica, que originariamente se refería al arte de las parteras que ayudaban a dar a luz, se ha convertido desde Sócrates en una metodología para reflexionar y enseñar ayudando a otro a "dar a luz" lo que llevaba dentro, a caer en la cuenta de algo que, de algún modo, ya se le había anunciado en su interior.

Esta mayéutica socrática, eminentemente pedagógica y filosófica, puede tener una versión teológica que nace de la convicción creyente de que el Espíritu del Señor está presente y guía la historia no solo de las personas, sino de los pueblos y de la humanidad, y que hay que saberlo descubrir y discernir en los signos de los tiempos (GS $4 ; 11 ; 44)$.

Los profetas de Israel descubren la voluntad y planes de Dios no mirando las nubes del cielo, sino oteando los acontecimientos de la historia que, como en la profecía de Ezequiel, está regada por una misteriosa corriente de agua que nace del templo y todo lo irriga, fecunda y sana (Ez 47). El mismo Jesús va descubriendo lenta y progresivamente la voluntad del Padre en su vida, cambia de parecer en Caná y acaba sanando a la hija de la siro-fenicia a la que al comienzo, desde una perspectiva nacionalista judía, había excluido de su misión.

Una teología mayéutica tiene que descubrir esta presencia misteriosa del Espíritu en la historia de las personas, de los pueblos, de la humanidad.

Una teología mayéutica ha de practicar un diálogo paciente, hacer preguntas para que el alumno descubra algo que ya tenía en su interior, pero que debía desarrollar, crecer y madurar. Esto supone pasar de clases magistrales a clases más participativas y dialogantes, talleres, seminarios donde sea posible escucharse mutuamente. ¿No era éste el sentido de las primeras universidades medievales que eran por definición universitas professorum et alumnorum, una comunidad de profesores y alumnos?

Pero además una teología mayéutica tiene que partir de la base de que la fe del teólogo profesor no es diferente o superior a la de los alumnos, que ambos tienen la unción del Espíritu y que entre todos se deben ayudar a alimentar la fe, a reflexionarla y vivirla. Sería falso identificar al teólogo con la Iglesia docente y a los alumnos con la Iglesia discente, en la Iglesia todos enseñamos y aprendemos. 
Esto se vuelve más urgente cuando se trata de alumnos que por su edad, género, cultura o condición social y eclesial viven en un contexto totalmente diferente al del profesor. Los laicos tienen una problemática que los religiosos y clérigos desconocemos, tanto en el orden profesional y político como en el familiar, privado y sexual. Las mujeres nos sorprenden con intuiciones que nunca habíamos sospechado. Lo mismo vale para los jóvenes, tanto para los que pertenecen a la cultura moderna y posmoderna como para los que pertenecen a las culturas originarias.

El texto evangélico sobre la exultación mesiánica de Jesús que alaba al Padre porque a los pequeños han sido revelados los misterios del Reino (Lc 10, 21-22), no lo hemos tomado teológicamente demasiado en serio. ¿No fueron los pastores, auténticos maleantes de aquel tiempo, los primeros en recibir el anuncio del nacimiento de Jesús? ¿No fueron una pareja de pobres ancianos los que reconocieron en aquella familia campesina que acudía al templo con su hijito al Salvador de las naciones y luz para la revelación de todos los pueblos, mientras los sacerdotes, escribas y fariseos que deambulaban en aquel momento por el templo no lo advirtieron?

La fe del pueblo pobre y sencillo, su religiosidad popular, sus expresiones de fe, su mismo credo, encierran grandes riquezas que muchas veces no tenemos en cuenta. Cuando el pueblo invoca con confianza al "Diosito" porque sabe que siempre le acompaña, cuando la gente besa al "Niño Manuelito" en Navidad, cuando piden ser bendecidos con agua bendita, cuando recorren el vía crucis y besan la cruz el Viernes Santo, cuando rezan por los difuntos y se santiguan al pasar ante un templo, cuando acogen a los necesitados, rezan ante una enfermedad, compran flores, cuidan la tierra con cariño y piden permiso para atravesarla con el arado, ¿no nos estarán revelando tal vez algo que los sabios y prudentes de este mundo desconocemos?

Pero más allá de estas dimensiones más personales, la teología mayéutica tiene que discernir los signos de los tiempos, ver lo que el Espíritu está diciendo a la Iglesia a través de movimientos sociales y políticos, protestas de jóvenes y mujeres, del clamor de los excluidos, de las culturas, de las diversas religiones, del clamor de la tierra maltratada.

Esta mayéutica histórica, que A. Torres Queiruga ha popularizado en teología ${ }^{12}$, nos abre a otras dimensiones, nos obliga a hacer y enseñar teología desde el suelo de la realidad histórica en la que vivimos.

12. A. Torres Queiruga, A revelación de Deus na realización do home, Vigo, 1985. 


\section{Teología que nace de la praxis y conduce a ella}

Cuando un superior religioso centroamericano, en los años setenta, en plena efervescencia de la teología de la liberación, que buscaba un lugar para enviar a algunos de sus estudiantes de teología, preguntó a una facultad de teología del Cono Sur cuál era la línea teológica que seguían, recibió la respuesta de que en aquella facultad se enseñaba una teología seria, una teología europea. En este caso, dijo el superior centroamericano, prefiero enviar a mis estudiantes a París, Frankfurt o Lovaina.

Una teología mayéutica que nace de la praxis y se abre a la praxis no puede pasar por alto la situación de injusta pobreza que sufre el pueblo latinoamericano, no puede dejar de escuchar su clamor. Desde esta perspectiva, los pobres se convierten en lugar teológico privilegiado, un lugar teológico que no anula los lugares teológicos clásicos (Escritura, Tradición, Magisterio), pero los actualiza e historiza. No es que el pobre sustituya a Cristo, como se ha intentado decir, sino que Cristo está presente en el pobre, y en el pobre es posible tener una experiencia espiritual y profunda del Evangelio, experiencia también fundante, porque, como dijo Benedicto XVI en el discurso inaugural de Aparecida, en la fe cristológica está implícita la opción por el pobre ${ }^{13}$.

Esto significa que una teología que se enseñe en América Latina no puede tomar como modelo e intentar imitar al máximo las teologías europeas y del Primer Mundo, sino que tiene que partir de la realidad de pobreza, injusticia, exclusión, diversidad cultural y religiosa del continente latinoamericano. A partir de esta praxis liberadora se configura una nueva forma de hacer teología, como "acto segundo".

No se puede seguir haciendo afirmaciones generales y esenciales, que son "verdades pero que no sirven para nada", como en el viejo y famoso cuento de De Mello sobre los paracaidistas que no saben dónde han caído y dos sacerdotes les dicen que están en un poste de teléfonos...

Una teología que nazca de la praxis y conduzca hacia ella ha de ser una teología profética que anuncie el Reino de Dios y que denuncie, que diga en qué consiste realmente que la tierra es don de Dios para todos, en qué consiste el que todos seamos hijos e hijas del mismo Padre, en qué consiste el pecado original o pecado del mundo aquí y ahora en un mundo de pobreza injusta y de exclusión generalizada, qué significa conversión y gracia, qué es seguir a Jesús en América Latina, qué tipo de Iglesia hemos de ir edificando entre todos, qué exige la configuración de una Iglesia local, qué significa la cruz y quiénes son los crucificados de la historia aquí y hoy, por qué hay mártires, por qué el pueblo tiene esperanza y lucha por un mañana mejor y no se suicida colectivamente...

13. Aparecida 392, Discurso inaugural 3. 
Pensar que solo la teología europea es seria es ingenuidad o pereza mental. La teología latinoamericana de la liberación, con todas sus limitaciones y posibles ambigüedades, con todas las complementaciones y nuevos horizontes que hoy vemos urgentes (mayor sensibilidad y apertura al género, a las culturas, a las religiones, a la ecología...) es legítima y necesaria en América Latina y todo el Tercer Mundo. Más aún, sus intuiciones fundamentales son válidas para toda la Iglesia católica universal.

\section{A modo de conclusión}

¿Es posible enseñar teología hoy?, nos preguntábamos al comienzo. La respuesta no es simplemente afirmar que sí o que no. Es posible si esta teología cumple todas estas condiciones que hemos reseñado: mistagógica, simbólica, narrativa, mayéutica y práxica, con todas sus implicancias no solo pedagógicas, sino teológicas.

Pero esto a su vez cuestiona el quehacer teológico de los teólogos en América Latina hoy. No se puede enseñar una teología que no se viva, que no se practique, que no se realice. Sería falso pretender comunicar algo en lo que no se cree. Lógicamente, la pregunta sobre nuestra praxis de enseñanza teológica revierte sobre nuestro quehacer teológico. ¿Qué clase de teólogos o teólogas somos, cómo hacemos teología hoy, desde dónde, con quiénes, cuáles son nuestras fuentes y nuestros lugares teológicos privilegiados, qué nos apasiona, qué nos duele, sabemos arrodillarnos ante el Misterio, nos dejamos llevar por el Espíritu que ungió a Jesús de Nazaret, hablamos en lenguas de fuego, leemos a los místicos, qué experiencia eclesial y pastoral tenemos, estamos cercanos a los pobres, a los jóvenes, a las mujeres, a los indígenas, quiénes son nuestros amigos, dónde vivimos, cuánto ganamos...?

La pregunta de Santo Tomás, en la Suma teológica, sobre si es posible que alguien enseñe algo a otro no es tan ingenua como tal vez pensábamos. Su respuesta es algo que nos compromete, pues en ella nos va la vida. Acabemos con uno de los cuentos de Anthony de Mello:

Todo el mundo sabía perfectamente que el Maestro tenía sus reservas contra la palabra "teología", tal como ésta suele ser entendida.

Cuando le preguntaron abiertamente la razón de ello, respondió:

"La teología se ha convertido en un mal, porque no es tanto una búsqueda de la Verdad cuanto un intento de mantener un sistema de creencias". ${ }^{14}$

Sin comentarios.

14. A. de Mello, Un minuto para el absurdo, Santander, 1993, p. 238. 